\title{
GEOMETRIC STYLE IN DESIGN OF URBAN LANDSCAPES
}

\author{
Milena Lakićević (D), Danka Kordić \\ University of Novi Sad, Faculty of Agriculture, Department of Fruit Science, Viticulture, \\ Horticulture and Landscape Architecture, Novi Sad, Serbia
}

\begin{abstract}
Designing landscapes in geometric style has a long history. Even open spaces in ancient Egypt, dating around $3000 \mathrm{BC}$, were shaped in a clear geometric form. Later throughout the history, geometric patterns evolved and the most impressive achievements in landscape architecture were reached in France during the period of baroque. Geometric patterns are also steady in Moorish and Islamic gardens and landscapes. Contemporary landscape designs rely on the heritage of previous epochs, but it is suited and adapted to the local environment and conditions. Geometric style is considered as formal or classical one and can be found in urban landscapes and parks worldwide. In this paper, we focused on an example from Serbia; we analyzed the design features of the main city park in town of Ruma, Serbia and proposed a new design concept in a geometric style. The presentation is supported by 2D and 3D graphical representations produced in SketchUp 2017 and Adobe Photoshop CS4. The special attention in the designing process was dedicated to plant material and selection of plants was determined by their visual and aromatic qualities. The new design included the constriction of water mirrors, using the reflection in water to enchase the aesthetic features of landscape elements.
\end{abstract}

Key words: geometric style, urban landscapes, landscape architecture, Ruma (Serbia)

\section{INTRODUCTION}

Urban landscapes can be designed in different manners, and two main styles are: geometric (classical, formal) and natural (informal) one (Vujković et al, 2014). Geometric style has its origins in designing exteriors in ancient Egypt, and has evolved and improved ever since. Natural or informal style is referred to the design that does not recognize a regular or strict geometric pattern and its origins had been developed in Chinese and Japanese gardens. Nowadays, both styles are used equally and, in addition, they can also be combined. Combining geometric and informal style can be done in two ways: one single design can have traits of both styles forming a mixed style or one project can be consisted of two parts designed in geometric style (usually smaller, representative part) and natural style (usually larger backyards), and these zones are being separated by the architectural object.

After having its first outset in ancient Egypt, geometric style continued developing in the medieval period. From that timeframe Moorish and Islamic gardens were especially notable; some elements of their design are being incorporated in what we now consider a classic style. The most important elements conveyed from Moorish gardens are using plant material with intense color and scent properties (Kluckert, 2007). During the period of renaissance and mannerism, landscape architecture was blooming in Italy, and their landscape design was recognizable by intense use of topiary forms of trees and shrubs; it should be noted that this horticultural practice was established and known even in ancient Rome, but reached its peak during the period of renaissance. However, geometric style in landscape architecture is usually associated with the French baroque, and the most famous examples of that epoch are Versailles Park and Park of Vaux-le-Vicomte, both designed by André le Nôtre in the $17^{\text {th }}$ century. Parks designed in later periods are simpler and used just some of the baselines established during baroque, such as symmetry and perspective principles (Motloch, 2001).

Landscape architecture nowadays relies on heritage from previous epochs, but at the same time aims to meet local conditions and fulfill contemporary demands. In this paper, we have demonstrated how geometric style can be applied in designing of urban zones on the example of the park in Ruma, Serbia.

\section{METHODS}

The aim of the paper was to analyze current and propose a new, geometric design for the park in Ruma. For that purpose we used several programs; for the representation of broader spatial context of the park we used R version 3.5.1 and QGIS version 2.18 (Figure 1), while the designing process was supported by SketchUp 2017 and Adobe Photoshop CS4 (Figures 2-4). 


\subsection{Description of the case study area}

Town of Ruma is located in the north-west part of Serbia (Figure 1a) and the park situated in the central part of the town (Figure 1b).

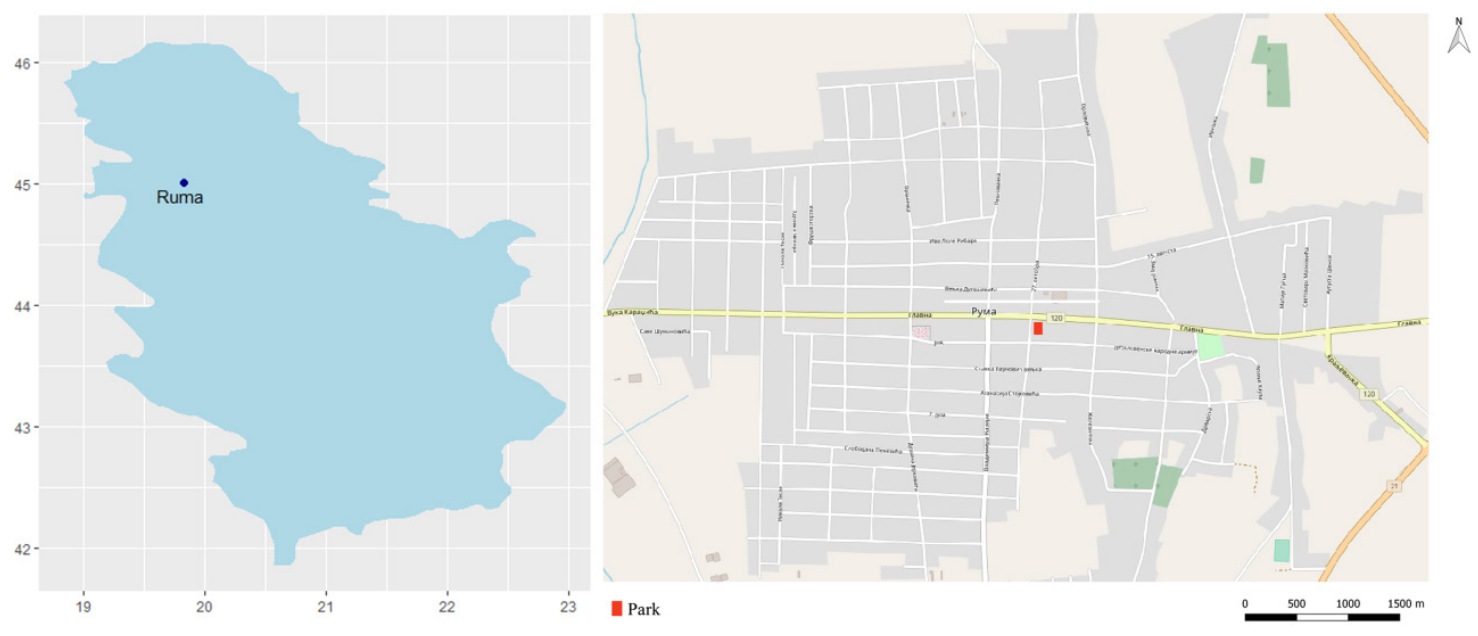

Figure 1a: Location of Ruma, Serbia

Figure 1b: Location of park in Ruma, Serbia

The park occupies $16.96 \mathrm{a}$, and due to its dimensions is often referred to as "small park" by the local inhabitants. The zone is primarily suited for children's play and the current design of the park has some of the geometric style features (Figure 2).

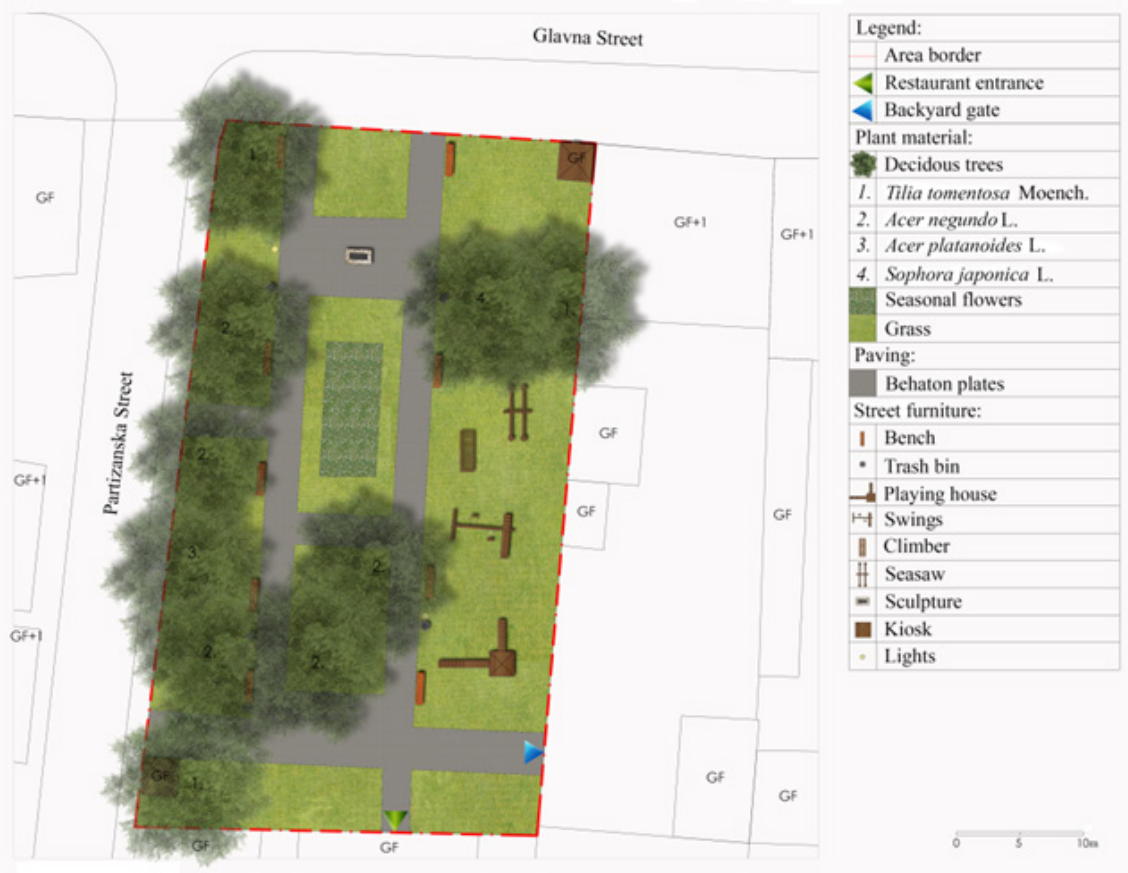

A

Figure 2: Current design of park in Ruma, Serbia

Next chapter explains one of the ways for introducing geometric style and proposes a new design for the park. One of the guidelines in the design process was to create a zone that would be appealing to larger number of visitors, and therefore promote tourist offer of the town (Tatović et al, 2014; Lakićević et al, 2011). 


\section{RESULTS}

The park has a parallelogram shape, and in order to introduce symmetry principle the area was transacted by vertical and horizontal axis in the first phase of the designing process. This way it was ensured that all park elements will be paired and ordered in accordance to the distance from these two axes. At the intersection of the axes, there is a tree of silver lime (Tilia tomentosa Moench.), that is the dominant element in the park. Placing a larger tree or a water element in the central part of park is one of the characteristics of geometric landscape style. This type of disposal of the landscape elements was set in both Moorish and French baroque gardens.

Selection of the plant material was an important part of the designing process and even though we were dealing with the smaller space the idea was to introduce diverse plant material. For the designing process 15 different plant species were selected based on their visual and aromatic qualities (Figure 3). Among them, there is a tree of Serbian spruce (Picea omorika (Pančić) Purk) which was selected as an endemic species in Serbia that can be grown in urban areas. Introducing endemic and endangered spaces when redesigning or reconstructing green areas is important for promoting biodiversity and protecting local floristic elements. In addition, introducing local flora gives an area an authentic feature, namely the area can be easily distinguished and unique by the plants that have been chosen.
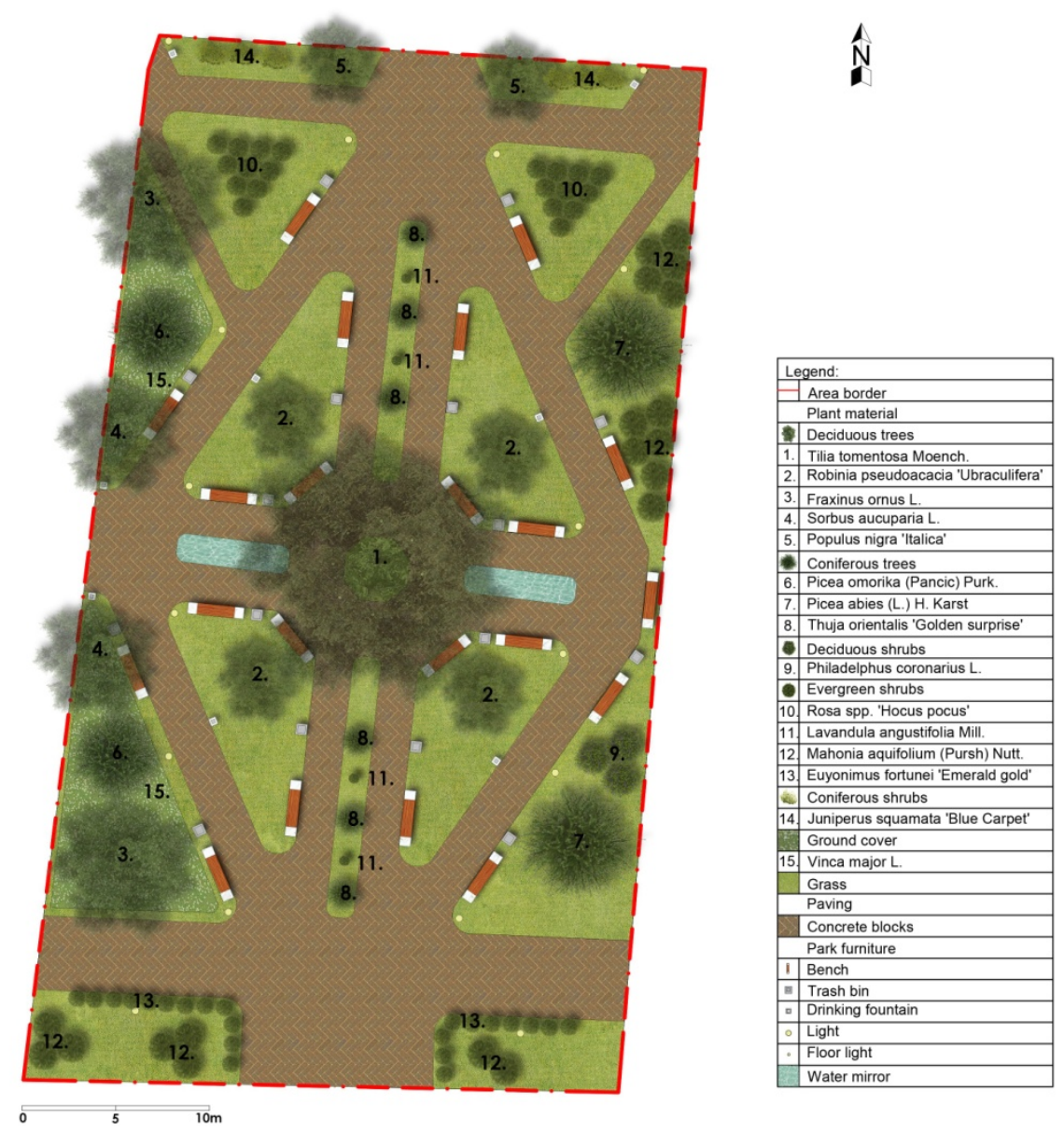

Figure 3: Proposed design of park in Ruma, Serbia

Some of the selected tree species proposed by new design such as, Thuja orientalis, Tilia tomentosa, Juniperus squamata, Mahonia aquifolium, etc. can be used for making topiary forms or hedges. Using these plants in the design was descended from Italian renaissance and French baroque gardens and it additionally emphases geometry pattern of the place. Besides that, some cultivars were selected based on the shape of tree crown and that is, for example, a form of black locust Robinia pseudoacacia 'Umbraculifera' which can be seen in many contemporary landscape architecture objects. Four trees of black locust were placed in the central part of the park on four large grass parterres. For emphasising 
shape of trees water mirrors were put on the horizontal axis of the park, in between central lime tree and four triangular grass parterres.

Selection of plants was also determined by their aromatic qualities, and based on this prerequisite some of the plants used in the proposed design are: Lavandula angustifolia, Philadelphus coronarius and Rosa spp. Using aromatic plants is a tradition of Moorish gardens from medieval period, and they have been intensively used in landscaping ever since.

The park is designed for a short stay of visitors and therefore there are benches placed all across the park as well as candelabras and ground lightening.

Parts of the park, not covered by plant material, are paved by concrete boards and serve as pathways throughout the area. The new design is also presented in $3 \mathrm{D}$ view in order to get a complete image of the area (Figure 4).

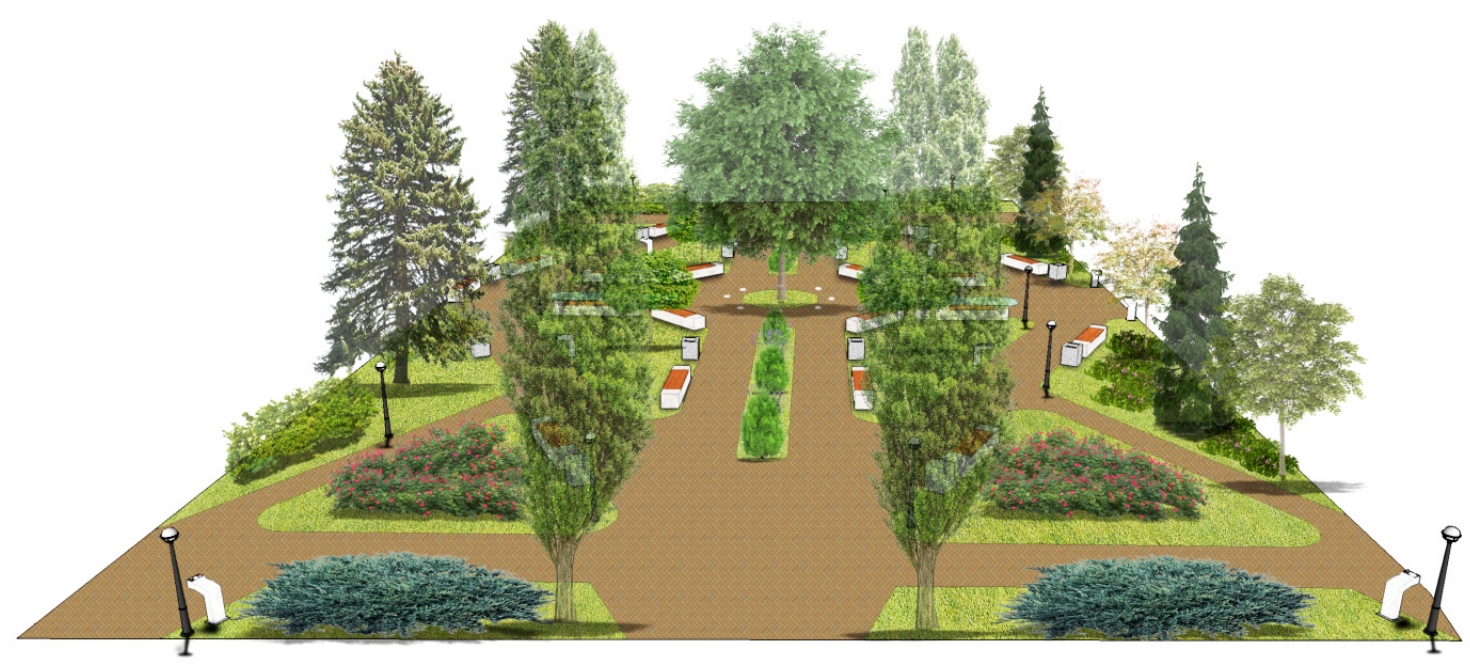

Figure 4: 3D view of proposed design of park in Ruma, Serbia

The above figure depicts height, shape and colour of new design elements and their disposition in the park.

\section{DISCUSSION}

In the new design proposal, symmetry principle was clearly respected and plant material was carefully selected in order to emphasize a strict geometric pattern of the park structure. Aside from choosing plant material, design process included planning of pathways and they were formed with the idea to make quick and easy communication throughout the area.

Even though some design elements were taken from the previous epochs, the main goal was to create a zone adjusted to contemporary demands and needs. New design is primarily suited for a short rest of local inhabitants.

Software used in this paper proved to be convenient for this type of research; QGIS and R can be applied for a spatial analysis on a broader scale, while SketchUp and Adobe Photoshop can be used for the detailed design process. It should be noted that $\mathrm{R}$ can also be used different analysis of plant material that are not used in this research, but are important from environmental point of view (for example analysis of biodiversity indices, etc.) (Lakićević, 2018).

\section{CONCLUSIONS}

Two main styles in designing urban landscapes are geometric (formal) and natural (informal) one. While formal style follows strict geometric principles, informal one doesn't recognize any geometric patterns. These styles can be also combined in designing parks and other urban green structures.

In this paper, we focused on the geometric style and have shown how its principles can be applied in designing of urban areas, on the case study of the park in Ruma, Serbia. Geometric style follows up some 
of norms established in previous epochs in development of landscape architecture. For designing the park in Ruma, we used some of the principles known and used from medieval time until nowadays.

From medieval time, the most of the ideas where descended from Moorish landscape architecture and that included the following: using aromatic plant species and placing water mirrors in central part of the place. From French baroque, main elements that were relied on are: symmetry principle and selection of plants that can be used for making topiary forms. Making topiary forms was initially developed in Italy, and can be also seen in Italian renaissance gardens. Disposal of the landscape elements in the park reminds of both medieval Moorish and French baroque gardens. However, it should be noted that all elements were suited for contemporary demands and needs. New designed space should be appropriate for short stays of visitors and should improve tourist offer of the town of Ruma.

\section{REFERENCES}

[1] Kluckert, E.: "European garden design: from classical antiquity to the present day", (Tandem Verlag $\mathrm{GmbH}$, Oxford, 2007.), pages 32-39.

[2] Lakićević, M., Srđević, B.: "Tourism evaluation of Topčiderski park in Belgrade", Zbornik naučnih radova Poljoprivrednog fakulteta 35(1), 127-135, 2011.

[3] Lakićević, M.: "Environment and sustainable development", (University of Novi Sad - Faculty of Agriculture, Novi Sad, 2018.), pages 13-21 (In Serbian).

[4] Motloch, J.L.: "Introduction to landscape design", (Willey, Austin TX, 2001.), pages 134-146.

[5] Tatović, N., Lakićević, M., Matić, V., Rabotic, B.: "Potential of Kalemegdan complex as a tourist attraction of Belgrade", Turističko poslovanje 14, 81-90, 2014. doi: 10.5937/TurPos1414081T.

[6] Vujković, Lj., Došenović, Lj.: "Garden design“, (University of Banja Luka - Faculty of Forestry, Banja Luka, 2014.), page 23 (In Serbian).

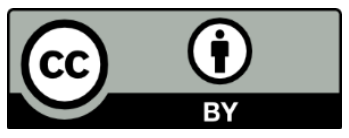

(C) 2018 Authors. Published by the University of Novi Sad, Faculty of Technical Sciences, Department of Graphic Engineering and Design. This article is an open access article distributed under the terms and conditions of the Creative Commons Attribution license 3.0 Serbia (http://creativecommons.org/licenses/by/3.0/rs/). 